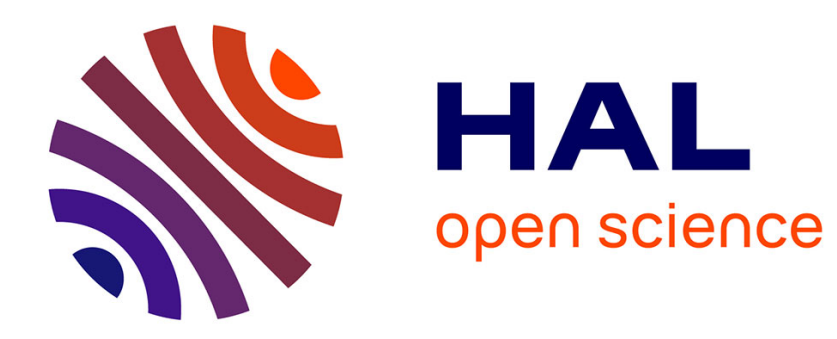

\title{
Energy Recovery Power Supply for Piezoelectric Actuator
}

Dejan Vasic, François Costa

\section{To cite this version:}

Dejan Vasic, François Costa. Energy Recovery Power Supply for Piezoelectric Actuator. IECON 2014, Oct 2014, Dallas, United States. hal-01697582

\section{HAL Id: hal-01697582 \\ https://hal.science/hal-01697582}

Submitted on 31 Jan 2018

HAL is a multi-disciplinary open access archive for the deposit and dissemination of scientific research documents, whether they are published or not. The documents may come from teaching and research institutions in France or abroad, or from public or private research centers.
L'archive ouverte pluridisciplinaire HAL, est destinée au dépôt et à la diffusion de documents scientifiques de niveau recherche, publiés ou non, émanant des établissements d'enseignement et de recherche français ou étrangers, des laboratoires publics ou privés. 


\section{Energy Recovery Power Supply for Piezoelectric Actuator}

\author{
Dejan Vasic \\ SATIE ENS Cachan \\ Universite de Cergy-Pontoise \\ Cachan, France \\ vasic@satie.ens-cachan.fr
}

\author{
François Costa \\ SATIE ENS Cachan \\ Universite de Paris Est Creteil \\ Cachan, France \\ costa@satie.ens-cachan.fr
}

\begin{abstract}
Piezoelectric actuators are used successfully to enable locomotion of micro-robot such as micro air vehicle with flapping wings. However, the use of piezoelectric actuators presents a major challenge for power electronic design: the input capacitance of such devices makes their use delicate because the instantaneous power may be much greater than the average effective power. Due to this challenge, conventional drive circuits, especially inductor, become too bulky or inefficient in low mass applications. This work describes a converter suitable to drive this kind of actuators with low inductor. Moreover the converter provides for recovery of the energy stored on the actuator capacitance back to the primary power supply when the actuator is not supply. The proposed converter is a DC/AC structure, which is capable of producing a square unipolar AC voltage. In our design, an auxiliary shunt circuits are connected to the actuator. Signal flow graph modeling, analysis and design of such a scheme is presented. Experimental validations have demonstrated the effectiveness of the proposed technique for recovery energy.
\end{abstract}

Keywords-piezoelectric actuator; power supply; energy recovery

\section{INTRODUCTION}

In recent years, a number of actuation methods are proposed or implemented in a micromechanical flapping insect, including piezoelectric [1], electrostatic [2] and dielectric elastomers [3]. It was shown that the piezoelectric actuator could promise the requirements of strict lightweight and high power density. Therefore, several robotic insects adopted the piezoelectric actuator, such as the robotic insects developed in our project "ANR EVA" (Fig. 1) and "Harvard Micro-robot Fly" [4] which is the first robot with flapping wings to get off with an external power supply. For biomimetic locomotion applications (e.g., flying, walking, or jumping), the overall size and weight are limited. Thus, there are critical limitations on the actuator and it's driving electronics. To produce a mechanical actuation, piezoelectric element requires a high electric field, so the high voltages ranging from ten to several hundred volts are usually required [5-10]. Different piezoelectric actuators were available: thick PZT (Ferroperm Piezoceramics), PZT fibers composite (Smart Material) and Thunder ${ }^{\circledR}$ (Face International). There were already several comparative studies of these actuators [11-14]. Due to the clamped capacitance, the piezoelectric devices are absorbing reactive energy. Accordingly, power converters always need to supply high levels of reactive power, or equivalently high power peaks compared to average power, leading to an overdesign of power converters, especially the magnetic component like inductor. Therefore, power factor optimization has recently been the subject of numerous investigations [1520]. In other hand, to avoid an overdesign of power converters due to the switching losses a zero-voltage-switching (ZVS) technique can be introduced [21]. But, to achieve the ZVS condition, a bulky inductor or an inductive matching network is typically required in the driving circuit [22]. However, the added magnetic component sacrifices the size and the weight of the converter. Although an inductor-less half-bridge circuit is possible [23], it only exists in a narrow bandwidth near the resonance frequency of the piezoelectric element. Therefore, to overcome these drawbacks and to recovery energy stored in the clamped piezoelectric capacitance, in this paper, an auxiliary shunt circuit is added at the half-bridge which enables us to decrease the reactive energy and the overall size of the power converter. The auxiliary shunt circuit includes a diode, a switch and a small inductor. The inductance is not in the path of the major power flow, thus it is not designed with piezoelectric drive frequency. The auxiliary circuit included the return of the electrical energy stored in the piezoelectric actuator capacitance back to the primary power supply when the actuator is turned off. The energy recovery was accomplished with high efficiency by using the resonance between the capacitance of the actuator and an external inductor. This switching shunt technique consists in connecting the piezoelectric actuator to the shunt circuit for a brief time period. This connection leads to a smooth inversion of the piezoelectric voltage, which induces an energy transfer from capacitance to supply source. The consequences of such size reductions involve new opportunities for designing ultra compact, low-cost wide bandwidth power amplifiers for piezoelectric actuators in a micro-robot application.

The paper is organized as follow: the second section summarizes the electrical behavior and drive requirements of the actuators. In section 3 and 4, the circuit topologies suitable for driving the high-voltage actuator in micro robotic 
applications by using a voltage supply are presented. Finally, the last section concludes the paper.

\section{Piezoelectric Actuator Model}

The piezoelectric actuator Thunder ${ }^{\circledR}$ provided by the company Face International Corp, is used in this work. The actuator consists of a thin layer of piezoelectric ceramic PZT bonded to an electrically conductive substrate and a layer of epoxy. The actuator is pre-stress, such that the piezoelectric ceramic is in a state of compression and the substrate is in a state of tension. The actuation of the Thunder is produced in bending mode induced by the applied voltage. However, the actuation displacement reaches only a few millimeters even when it is operated as its natural frequency. The limited displacement of the actuator is amplified by a mechanical system, which also transforms the bending motion of the actuator into a large wing flapping. In order to obtain an insect flight with flapping wings including aerodynamics, structural dynamics and control consideration, the two wings are drive separately, and two Thunders are used. The piezoelectric actuators were driven at the first resonant frequency (about $100 \mathrm{~Hz})$.

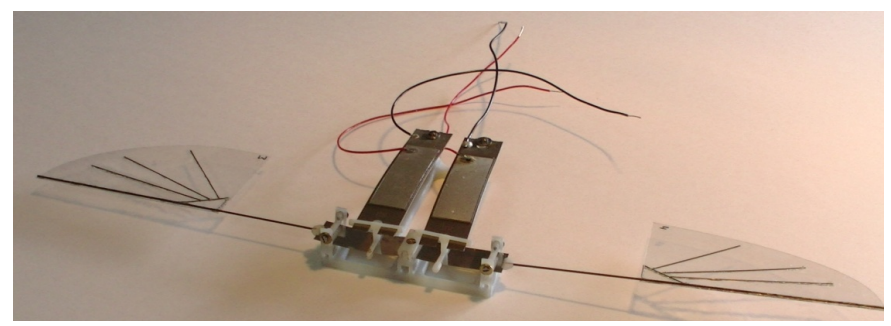

Fig. 1. Piezoelectric actuators Thunder for flapping wings (CEA LETI)

Smart structures, as piezoelectric actuator, is usually analyzed by a lumped model based on the variational principle. This model received considerable attention since the 1970s, and the formulation presented by Alik et al. For simplicity, the model used in this paper involves one piezoelectric element and has one degree of freedom. Indeed, a mechanical model based on only one degree of freedom gives a good description of the vibrating structure behavior near one of its resonant frequencies. Close to one of the resonant frequencies, the dynamic behavior and governing equations of the structure can therefore be written as equations (1) and (2).

$$
\begin{aligned}
& M \ddot{u}+D \dot{u}+K^{E} u+\alpha V_{P}=0 \\
& I=\alpha \dot{u}-C_{P} \dot{V}_{P}
\end{aligned}
$$

where $M$ is the mass, $D$ is the damping coefficient, the spring coefficient $\mathrm{K}^{\mathrm{E}}$ is the device stiffness, $\alpha$ is force-voltage coupling factor, $I$ is outgoing current generated from the piezoelectric element, $C_{P}$ is clamped capacitance of the piezoelectric element and $u$ is displacement of the system.

The electric equivalent circuit of the actuator is shown in Figure 2. The circuit consists of a static part, which is represented by the clamped capacitance $C_{\mathrm{P}}$, and a resonant branch which is corresponding to the first mechanical vibration mode. In the resonant branch, inductor $L_{\mathrm{m}}$, resistor
$R_{\mathrm{m}}$ and capacitor $C_{\mathrm{m}}$ are equivalent to the mass, the mechanical damping, and the stiffness of the first vibration mode respectively. The current $i_{\mathrm{m}}$ flowing in the mechanical resonant branch is equivalent to the vibration velocity of the actuating structure. The dielectric losses are neglected.

TABLE I. THUNDER ACTUATOR DIMENSIONS

\begin{tabular}{|c|c|c|}
\hline Mass & Footprint & Thickness \\
\hline $2.1 \mathrm{~g}$ & $63.25 \mathrm{~mm} \times 13.12 \mathrm{~mm}$ & $0.43 \mathrm{~mm}$ \\
\hline
\end{tabular}

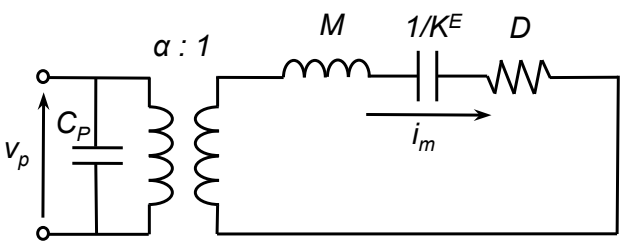

Fig. 2. Equivalent circuit of the piezoelectric actuator

The piezoelectric parameters of the actuator have been characterized and are summarized in Table 2.

TABLE II. MODEL PARAMETERS

\begin{tabular}{|c|c|c|}
\hline Symbol & Description & Value (unit) \\
\hline$f_{\mathrm{sh}}$ & Short circuit resonant frequency & $100.6 \mathrm{~Hz}$ \\
\hline$f_{o p}$ & Open circuit resonant frequency & $100.77 \mathrm{~Hz}$ \\
\hline $\mathrm{K}^{\mathrm{E}}$ & $\begin{array}{c}\text { Equivalent stiffness when short } \\
\text { circuit }\end{array}$ & $1 / 0.0028$ \\
\hline $\mathrm{M}$ & Mass & $12.10^{-3} \mathrm{~kg}$ \\
\hline $\mathrm{D}$ & Damping coefficient & 0.01 \\
\hline$\alpha$ & Force-voltage factor & $0.004 \mathrm{~N} / \mathrm{V}$ \\
\hline $\mathrm{k}^{2}$ & Coupling factor & 0.0037 \\
\hline
\end{tabular}

The main objective of the proposed technique is to reduce consumption of reactive power, to optimize the active power and a full suppression of the reactive power at all working frequencies including close to the resonant one. The energy transferred to the piezoelectric actuator can be described with the following equations:

$$
\begin{aligned}
& \int_{0}^{T} M \ddot{u} \dot{u} d t+\int_{0}^{T} D \dot{u}^{2} d t+\int_{0}^{T} K u \dot{u} d t+\int_{0}^{T} \alpha v_{P} \dot{u} d t=0 \\
& \int_{0}^{T} i_{P} v_{P} d t=\int_{0}^{T} \alpha v_{P} \dot{u} d t-\int_{0}^{T} C_{P} v_{P} v_{P} d t
\end{aligned}
$$

where $\int_{0}^{T} M \ddot{u} \dot{u} d t$ is the kinetic energy during one period, $\int_{0}^{T} K u \dot{u} d t$ is the potential energy, $\int_{0}^{T} D \dot{u}^{2} d t$ is the mechanical energy, $\int_{0}^{T} i_{P} v_{P} d t$ is the electrical energy provided by the power amplifier. Accordingly, the active power is:

$$
P=\frac{1}{T} \int_{0}^{T} i_{P} v_{P} d t
$$


For the equation (4), $\int_{0}^{T} \alpha v_{P} \dot{u} d t$ is the energy transferred in mechanical part and $\int_{0}^{T} C_{P} v_{P} v_{P} d t$ is the energy stored in the clamped capacitance $C_{P}$. This energy in capacitance $C_{P}$ is a reactive energy that must be managed and recovery back to the primary source when actuator is not supply to avoid to oversize the power supply.

\section{POWER SUPPly WITH ENERGY ReCOVERY}

Owing to the clamped capacitor $C_{\mathrm{p}}$, in addition of the high levels of reactive power, a square driving signal will generate large losses in the switches. Therefore, a series or parallel inductor is typically added to the piezoelectric actuator to ensure the ZVS condition in the power stage, but the inductor is bulky in low frequency application (around hundred henry) and too heavy for flying micro-robot application. Accordingly, the circuit topology is proposed to limited reactive energy without any bulk inductor. The circuit topology is shown in Figure 3. There are four $n$-channel power MOSFETs switches $K_{1}, K_{2}, S_{1}$ and $S_{2}$. The switches $K_{1}$ and $K_{2}$ are operated as a halfbridge circuit, and their parasitic capacitors are denoted by $C_{\mathrm{K} 1}$ and $C_{\mathrm{K} 2}$ respectively. The actuator with input capacitance $C_{\mathrm{P}}$ is connected to the middle point of the switches $K_{1}$ and $K_{2}$. The half-bridge switches generate a trapezoidal waveform of the voltage $v_{p}$ applied to the input terminal of the actuator. The input voltage $v_{p}$ excites the mechanical vibration and induces the input current $i_{p}$. This input current $i_{p}$ is the sum of the virtually mechanical current $i_{m}$ of the actuator that is equivalent to the vibration velocity and the charging and discharging current of the capacitance $C_{\mathrm{P}}$. Switches $S_{1}, S_{2}$ and inductor $L$ are also connected to the input terminal of the actuator. These shunt circuit is only switched-on during the dead time of the half-bridge (switches $K_{1}$ and $K_{2}$ ). In practice, inductor $L$ is small, so there is no bulk inductor in the implemented circuit. For simplicity, there are some assumptions for the understanding of this circuit: the parasitic capacitors of switches $S_{1}$ and $S_{2}$ are neglected, as they do not influence the waveforms mainly leaded by the capacitance of the actuator.

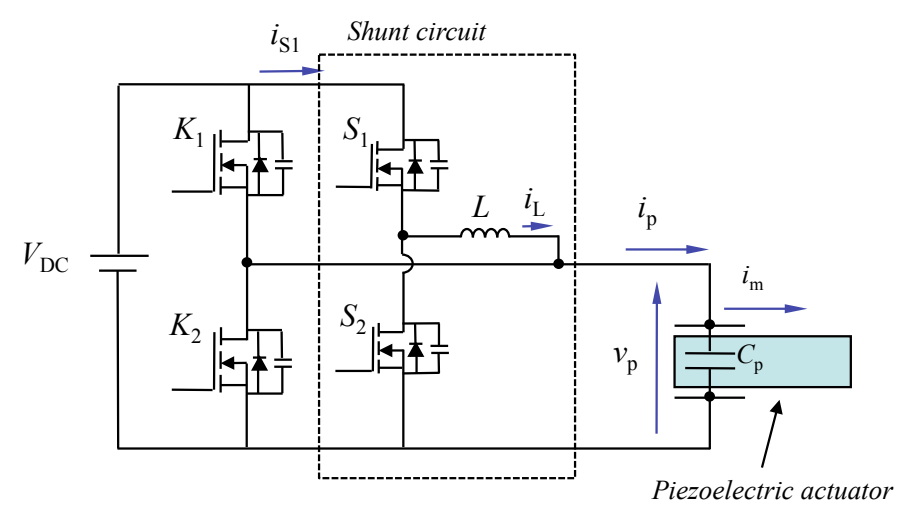

Fig. 3. Circuit topology of DC/AC proposed converter

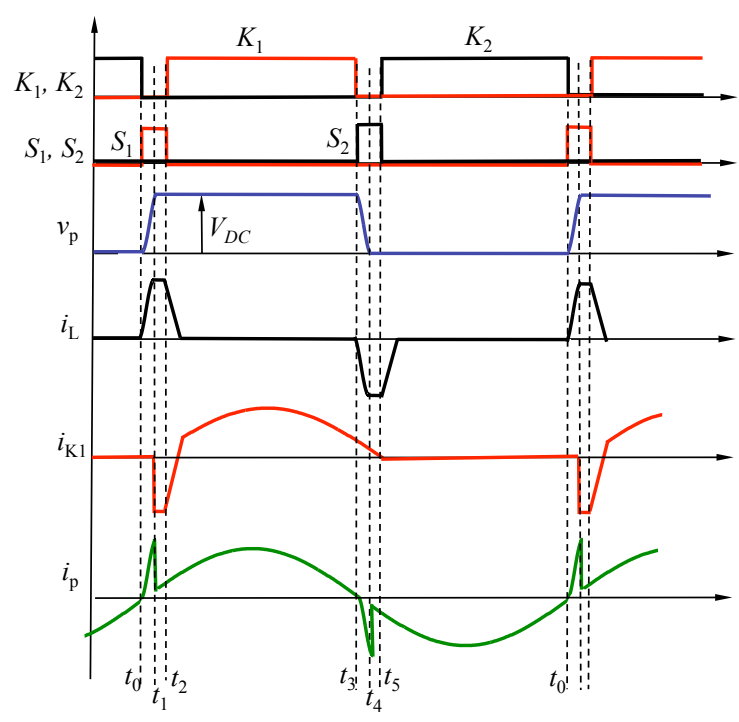

Fig. 4. Theoretical waveforms

\section{A. Principle of operation}

The ideal key-waveforms of the driving circuit operating at resonance frequency of actuator presented in Figure 4 are used to explain the principle of operation. The circuit operation is mainly categorized into six steps.

Step $1\left[t_{0}<t<t_{1}\right]$ Figure 5-a: The high-side switch $S_{1}$ is ON and the switches $K_{1}, K_{2}$ and $S_{2}$ are OFF. The capacitor $C_{\mathrm{p}}$ is charged through the inductor $L$. It should be noted that capacitor $C_{\mathrm{p}}$ contribute to the resonance with inductor $L$ in this step. Voltage $v_{p}$ increases sinusoidally until reaching $V_{\mathrm{DC}}$ and the current in inductor $L$ increases until reaching $V_{D C} \sqrt{C_{P} / L}$. If the charging time during the period is not large enough, capacitor $C_{\mathrm{p}}$ cannot be fully charged to $\mathrm{V}_{\mathrm{DC}}$ and the high-side switch $K_{1}$ cannot be turned $\mathrm{ON}$ at zero voltage in the following step. Therefore, this step must be larger than the period of resonance between $L$ and capacitance $C_{\mathrm{P}}$ :

$$
t_{1}-t_{0}=\frac{\pi}{2} \sqrt{L C_{P}}
$$

which is a quarter of the resonant period of the $\mathrm{L}-\mathrm{C}_{\mathrm{P}}$ series resonant circuit. According to Eq. (6), a small inductance is required with the small time interval $\left(t_{1}-t_{0}\right)$ under the given capacitances. This is the underlying reason why we can adopt a small value inductance. This step is over when capacitor voltage reaches $\mathrm{V}_{\mathrm{DC}}$, diode $D_{1}$ automatically turns on and keeps the voltage across the capacitor at $\mathrm{V}_{\mathrm{DC}}$.

Step 2. [t $1<t<t 2]$ Figure 5-b: During this step, switch $S_{1}$ is still ON and the switches $K_{1}, K_{2}$ and $S_{2}$ are still OFF. The input voltage $v_{p}$ is equal to $\mathrm{V}_{\mathrm{DC}}$. During this period, the body diode $D_{1}$ of switch $K_{1}$ is forward bias in order to support constant current $i_{\mathrm{L}}$. The current in the inductor $\mathrm{L}$ will free wheel around the $\mathrm{S}_{1}$-L- $\mathrm{D}_{1}$ loop. This step is over until switch $\mathrm{K}_{1}$ is turned ON and $S_{1}$ is turned OFF.

Step 3. $[t 2<t<t 3]$ Figure 5-c: The high-side switch $\mathrm{K}_{1}$ is $\mathrm{ON}$ and the low-side switch $\mathrm{K}_{2}$ is OFF. The shunt circuits $\mathrm{S}_{1}$ and $\mathrm{S}_{2}$ are both OFF. During this period, the body diode of switches $K_{1}$ and $S_{2}$ are forward bias in order to support current 
$i_{L}$ flowing back to power supply decreasing in time at a rate $L \frac{d i}{d t}=V_{D C}$. The energy stored in the inductor $\mathrm{L}$ can be recovered to the power supply. In the same time, the sinusoidal mechanical current $i_{m}$ is flowing through the switch $\mathrm{K}_{1}$ and the actuator.

Step 4. $\left[t_{3}<t<t_{4}\right]$ Figure 5-d: The high-side switch $K_{1}$ is OFF and the low-side switch $S_{2}$ is ON. The capacitor $C_{\mathrm{p}}$ is charged through the inductor $L$. The discharge time is a quarter of the resonance period of the $L-C_{\mathrm{P}}$ resonance circuit. This step is over when capacitor voltage reaches 0 , body diode $D_{2}$ of switches $K_{2}$ automatically turns on. It is similar as step 1 .

Step 5. $\left[t_{4}<t<t_{5}\right]$ Figure 5-e: During this step, switches $\mathrm{S}_{2}$ are still OFF. During this period, the body diode $D_{2}$ of switch $K_{2}$ is forward bias in order to support current $i_{\mathrm{L}}$. The current in the inductor $L$ will free wheel around the $\mathrm{S}_{2}-\mathrm{L}-\mathrm{D}_{2}$ loop. This step is over until switch $\mathrm{K}_{2}$ is turned $\mathrm{ON}$ and $S_{2}$ is turned OFF. It is similar as step 2.

Step 6. $\left[t_{5}<t<t_{0}\right]$ Figure 5-f: The high-side switch $\mathrm{K}_{1}$ is OFF and the low-side switch $K_{2}$ is $O N$. The shunt circuits $S_{1}$ and $S_{2}$ are both OFF. During this period, the body diode of switches $\mathrm{K}_{2}$ and $\mathrm{S}_{1}$ are forward bias in order to support current $i_{L}$ flowing back to power supply, decreasing in time at a rate $L \frac{d i}{d t}=V_{D C}$. The energy stored in the inductor $L$ can be recovered to the power supply. In the same time, the sinusoidal mechanical current $i_{m}$ is flowing through the switch $\mathrm{K}_{2}$ and the actuator.

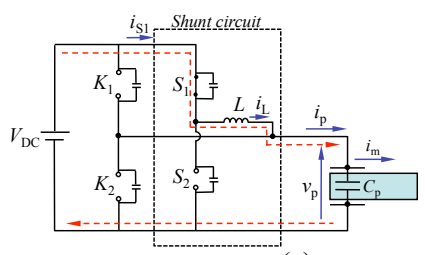

(a)

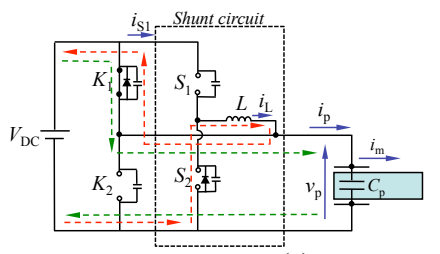

(c)

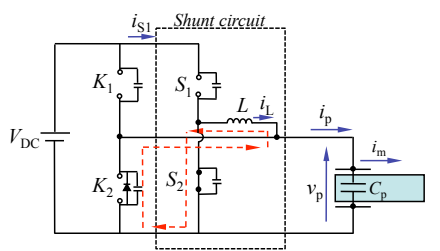

(e)

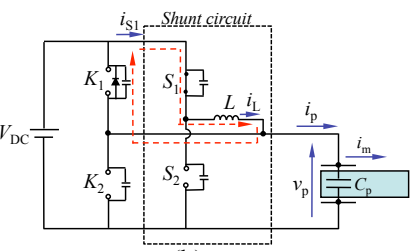

(b)

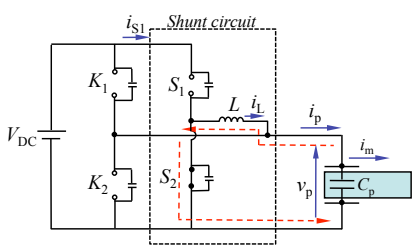

(d)

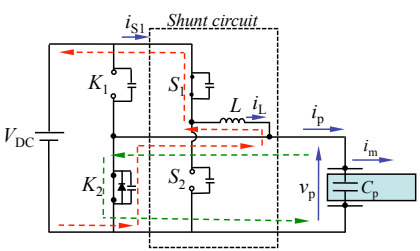

(f)
Fig. 5. Equivalent circuits of proposed DC/AC converter in different steps (a) Step $1\left[\mathrm{t}_{0}-\mathrm{t}_{1}\right]$ (b) Step $2\left[\mathrm{t}_{1}-\mathrm{t}_{2}\right]$ (c) Step $3\left[\mathrm{t}_{2}-\mathrm{t}_{3}\right]$ (d) Step $4\left[\mathrm{t}_{3}-\mathrm{t}_{4}\right]$ (e) Step 5 $\left[t_{4}-t_{5}\right](f)$ Step $6\left[t_{5}-t_{0}\right]$
In brief summary, the main power switches $K_{1}$ and $K_{2}$ are turned $\mathrm{ON}$ in steps 3 and 6 respectively. During the other steps, switches $K_{1}$ and $K_{2}$ are both OFF, which are the dead time in the half-bridge circuit. In steps 1 and 4 the capacitor of the actuator is resonantly charged or discharged by the shunt circuits through the inductor. Once they are achieved, the currents in the inductor of the shunt circuit are recovered in steps 3 and 6.

\section{B. Optimal value of inductor}

To optimize the reactive energy in the system which decrease the input power source and in the same time to decrease the size of the inductors the amplitude of the input current must be limited. In other words, the amplitude of current in auxiliary shunt circuits must be the same than the fundamental current at resonance of piezoelectric actuator. The amplitude of current in auxiliary shunt circuit is given by the resonance between $\mathrm{L}$ and $\mathrm{C}_{\mathrm{p}}, I_{S}^{\operatorname{Max}}=V_{D C} \sqrt{C_{P} / L}$. At the resonance the power supplied by the amplifier is given by:

$$
P_{\text {piezo }}=V_{P 1}^{R M S} I_{P}^{R M S}=\frac{2 V_{D C}}{\pi \sqrt{2}} \cdot \frac{I_{P}^{M a x}}{\sqrt{2}}
$$

Where $V_{P 1}^{R M S}$ and $I_{P}^{R M S}$ is the RMS value of the fundamental of the voltage $v_{p}$ and the RMS value of the piezoelectric mechanical current at the resonance respectively. $I_{P}^{M a x}$ is the magnitude of the mechanical current at the resonance. $\mathrm{P}_{\text {piezo }}$ is the active power at the input of the piezoelectric actuator $P_{\text {piezo }}=\frac{2 V_{D C}^{2} \alpha^{2}}{R_{m} \pi^{2}}$. The optimal inductor is obtained when the magnitude of the current in auxiliary circuit is equal to magnitude of the mechanical current at the resonance.

$$
L=\frac{C_{P}}{\left(\frac{2 \alpha^{2}}{R_{m} \pi}\right)^{2}}
$$

\section{EXPERIMENTAL RESULTS}

The experimental setup is shown in Figure 6, in which the tested piezoelectric actuator is Thunder TH-8R from company FACE. The signal processing to generate pulse to drive the switches is performed by two monostables and two xor (Figure 6). All measuring signals are simply monitored using an oscilloscope. The following specifications and components were adopted in our experiment: $V_{\mathrm{DC}}=75 \mathrm{~V}$; the four switches $K_{1}, K_{2}, S_{1}$ and $S_{2}$ : IRF 640; constant dead time, i.e. $\left(\mathrm{t}_{2}-\mathrm{t}_{0}\right)$ and $\left(t_{5}-t_{3}\right): 0.15 \mathrm{~ms}$. The inductor value has been set in order to limit the spike current during quarter-period of the resonant instant (when the piezoelectric voltage changes from 0 to $V_{D C}$ and from $V_{D C}$ to 0 ) using equation (8). The objective is to minimize the apparent power, which appear when the piezoelectric clamped capacitance is charging or discharging. In the case of the piezoelectric actuator Thunder, the clamped capacitance of the piezoelectric layer is close to $25 \mathrm{nF}$. The good performances are obtained with an inductor value of $20 \mathrm{mH}$. All component values are shown in table 3. 


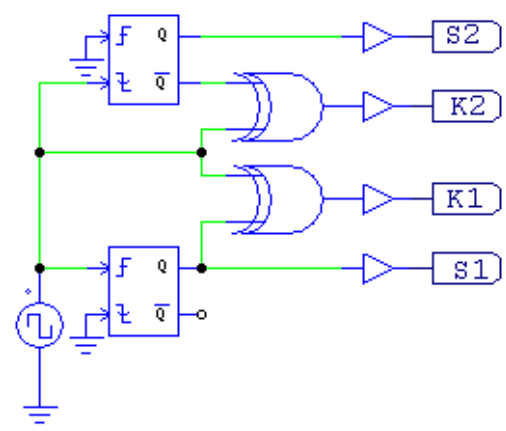

Fig. 6. Signal processing to drive switches

TABLE III. COMPONENT VALUES

\begin{tabular}{|c|c|c|}
\hline Symbol & Description & Value (unit) \\
\hline $\mathrm{K}_{1}, \mathrm{~K}_{2}, \mathrm{~S}_{1}, \mathrm{~S}_{2}$ & Transistors MOSFET & IRF 640 \\
\hline $\mathrm{L}$ & Inductor & $20 \mathrm{mH}$ \\
\hline $\mathrm{V}_{\mathrm{DC}}$ & Input voltage & $75 \mathrm{~V}$ \\
\hline $\mathrm{C}_{\mathrm{P}}$ & Piezoelement capacitance & $25 \mathrm{nF}$ \\
\hline $\mathrm{t}_{3}-\mathrm{t}_{0}$ & Dead time & $0.15 \mathrm{~ms}$ \\
\hline & Monostable & 4538 \\
\hline & XOR & 4070 \\
\hline & MOS Driver & IRF 2108 \\
\hline & \multicolumn{2}{|}{} \\
& \multicolumn{2}{|c}{} \\
& \multicolumn{2}{|c|}{}
\end{tabular}

Figure 7 shows the picture of the converter. Figures 8 to 11 show the experimental waveforms of $\mathrm{S}_{1}$ and $\mathrm{S}_{2}$ driving signals, piezoelectric voltage $v_{p}$, inductor current $i_{L}$, and piezoelectric current $i_{P}$ at the mechanical resonance $100.6 \mathrm{~Hz}$. It can be seen that the experimental waveforms are in excellent agreement with the theoretical and simulation predictions. We have tested the converter with frequency range from $10 \mathrm{~Hz}$ to $500 \mathrm{~Hz}$ and a constant dead time, i.e. $0.15 \mathrm{~ms}$. The experimental results have verified that the proposed circuit can recover energy in a wide bandwidth without the use of a bulky inductor and thanks to a minor complication of the circuit with ancillary low losses semiconductors. The analysis of these figures leads to conclude that the auxiliary circuits, during dead time, charge and discharge the clamped capacitance trough inductor, which justifies the reduction of the power consumption.

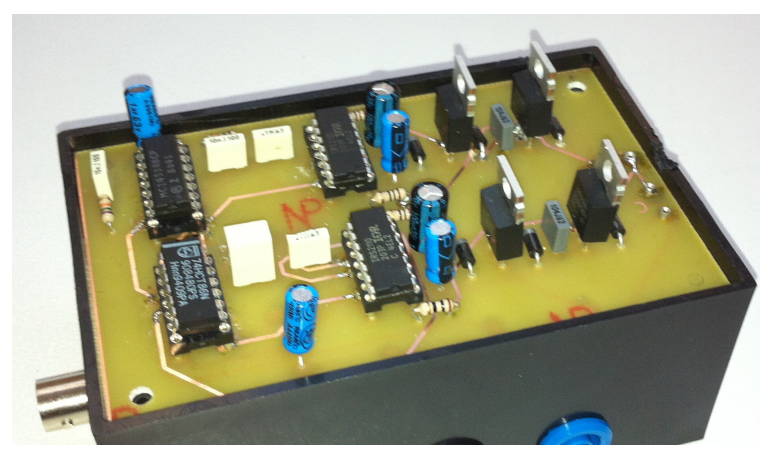

Fig. 7. Picture of the proposed DC/AC converter

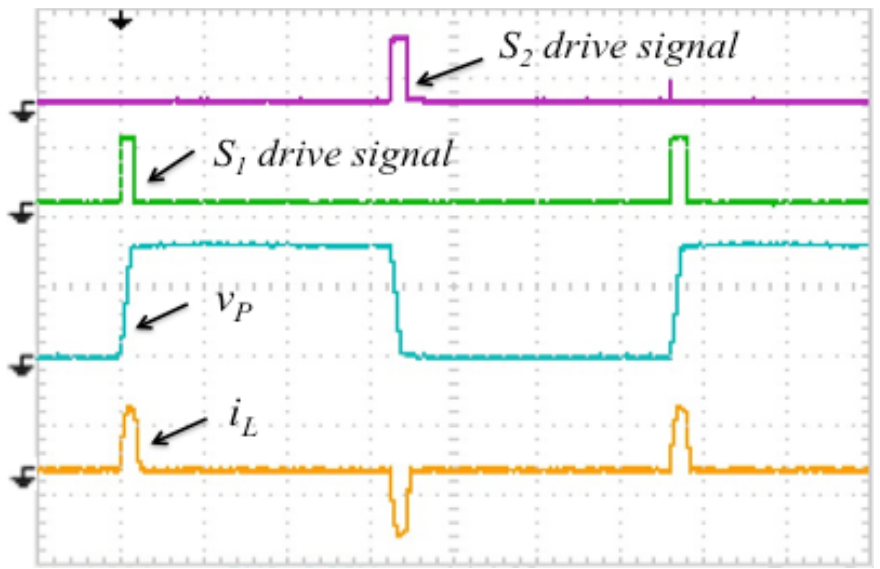

Fig. 8. Experimental waveforms: $S_{2}$ drive signal $(10 \mathrm{~V} /$ div $), S_{1}$ drive signal $(10 \mathrm{~V} / \mathrm{div})$, voltage $\mathrm{v}_{\mathrm{P}}(50 \mathrm{~V} / \mathrm{div})$ and current $\mathrm{i}_{\mathrm{L}}(100 \mathrm{~mA} / \mathrm{div})$

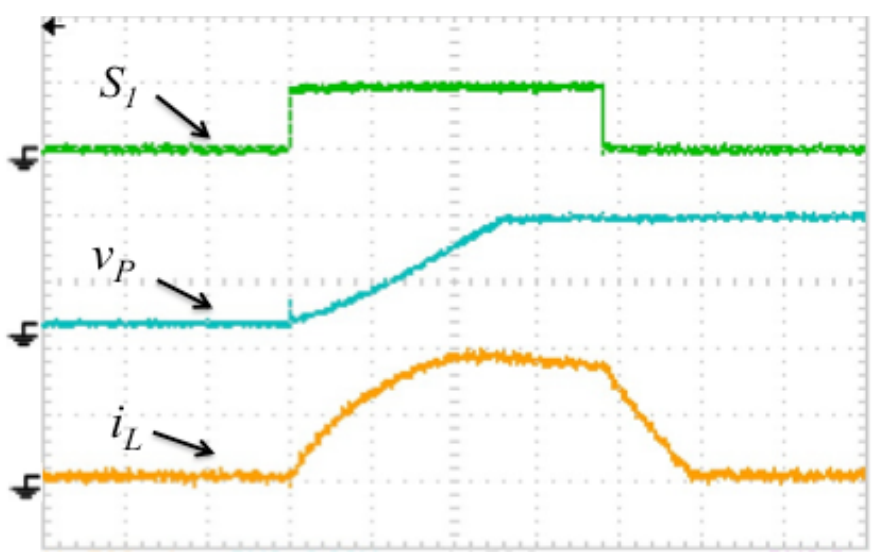

Fig. 9. Experimental waveforms: $S_{1}$ drive signal $(10 \mathrm{~V} /$ div $)$, voltage $v_{P}$ $(50 \mathrm{~V} / \mathrm{div})$ and current $\mathrm{i}_{\mathrm{L}}(50 \mathrm{~mA} / \mathrm{div})$

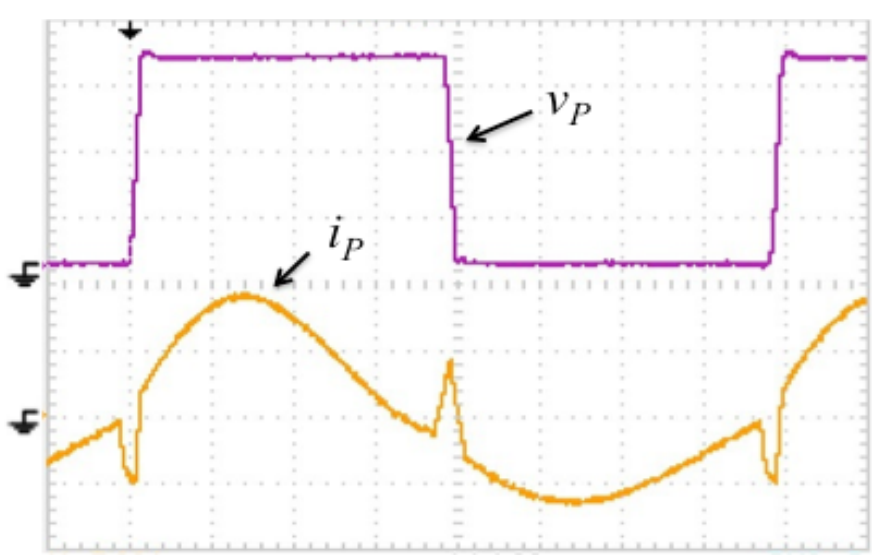

Fig. 10. Experimental waveforms: voltage $v_{P}(20 \mathrm{~V} /$ div $)$ and current $i_{L}$ (50 $\mathrm{mA} / \mathrm{div})$

Figure 11 shows the experimental active power versus frequency. The maximum power transmitted at the resonance is $390 \mathrm{~mW}$. We notice that the power converter with recovery 
technique can provide enough active power and minimize the reactive power.

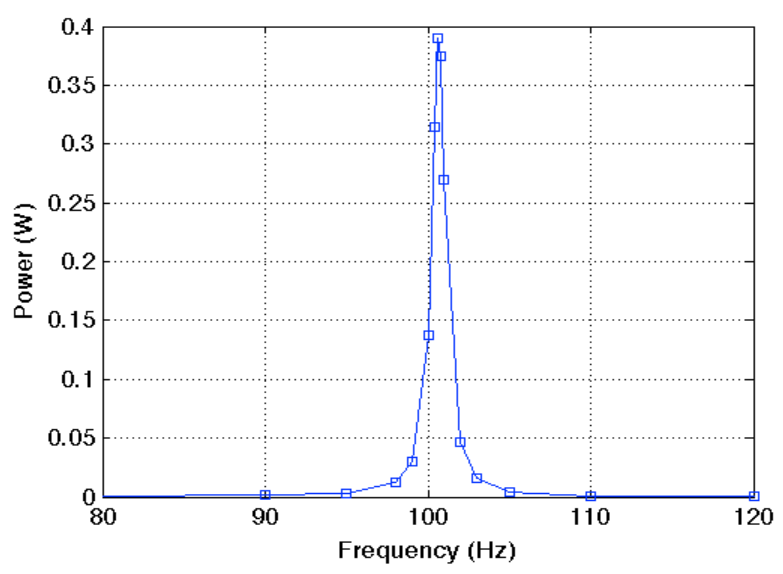

Fig. 11. Experimental output power

\section{CONCLUSION}

A new circuit for driving a piezoelectric actuator with square waveforms has been presented analytically and verified experimentally and includes recovery of the electrical energy stored in the capacitance of the actuator back to the primary power supply. A shunt circuit with small inductor is connected to the input terminal of the actuator in order to transfer energy from piezoelectric clamped capacitance to power supply during when the actuator is turned off. The proposed control law is very simple and can be easily implemented. During the dead time of the main switches, the capacitor of the actuator is resonantly charged or discharged by the shunt circuits through the inductor. This approach is independent of the piezoelectric characteristics, thus allowing very large frequency range operation. Since the recovery energy can be achieved without any bulky inductor, the proposed circuit may be significantly smaller, which could be an advantage in some applications.

\section{ACKNOWLEDGMENT}

The authors are grateful to Eleceram Technology co. ltd. and Miézo Technology co. ltd. The funding of this project, from Agence Nationale de la Recherche (ANR, CNRS), France under EVA project, is gratefully acknowledged.

\section{REFERENCES}

[1] E. Steltz, M. Seeman, S. Avadhanula, and R. S. Fearing, "Power electronics design choice for piezoelectric microrobots," in IEEE/RSJ Int. Conf. on Intelligent Robots and Systems, pp. 1322-1328, 2006.

[2] S. Hollar, A. Flynn, C. Bellew, and K. S. J. Pister, "Solar powered 10 mg silicon robot," in Proc. IEEE Sixteenth Annual Int. Conf. on Micro Electro Mechanical Systems, pp. 706-711, 2003.

[3] R. D. Kornbluh, R. Pelrine; Q. Pei, R. Heydt, S. Stanford; S. Oh, J. Eckerle, "Electroelastomers: Applications of dielectric elastomer transducers for actuation, generation, and smart structures," in Proc. SPIE, vol. 4698, pp. 254-270, 2002.

[4] R. J. Wood, "Liftoff of a 60mg flapping-wing MAV," in IEEE/RSJ Int. Conf. on Intelligent Robots and Systems, pp. 1889-1894, 2007.
[5] N. Degrenne, B. Allard, F. Buret, F. Morel, SD Adami, D. Labrousse, "Comparison of 3 Self-Starting Step-Up DC:DC Converter Topologies for Harvesting Energy from Low-Voltage and Low-Power Microbial Fuel Cells," In Proc. EPE 2011, pp. 1-10, Birmingham UK, 2011

[6] Y.-P. Liu, D. Vasic, F. Costa, W.-J. Wu, Denis Schwander, "Fixed frequency controlled Piezoelectric 10W DC/DC converter," In Proc. IEEE ECCE'2010, pp. 3030-3037, Atlanta USA, September 2010

[7] Y.-P. Liu, D. Vasic, F. Costa, W. J. Wu., "Electromagnetic Interferences Analysis of DC/DC Converters Based on Piezoelectric Transformers," Jpn. J. Appl. Phys.,vol. 49, no. 6, 2010

[8] D. Vasic, F. Costa, E. Sarraute, "Comparing piezoelectric and coreless electromagnetic transformer approaches in IGBT driver," Eur. Phys. J. Appl. Phys. vol. 34, pp. 237-242, June 2006

[9] D. Vasic, F. Costa, E. Sarraute, P. Sangouard, E. Cattan, "Piezoelectric microtransformer based on PZT unimorph membrane," Journal of Micromechanics and Microengineering, vol. 14, no. 9, pp. S90-S96, September 2004

[10] D. J. Clingman and M. Gamble, "High voltage switching piezo drive amplifier," in Proc. SPIE, vol. 3674, 1999, pp. 280-286.

[11] Q. Wang, X. Du, B. Xu, and L. Cross, "Theoretical analysis of the sensor effect of cantilever piezoelectric benders," J. of Aplied Physics, vol. 85, pp. 1702-1712, 1999.

[12] R. J. Wood, E. Steltz, and R. S. Fearing, "Optimal energy density piezoelectric bending actuators," Sensors \& Actuators: A. Physical, vol. 119, no. 2, pp. 476-488, 2005.

[13] P. W. Robbins, "Simplified Unipolar, Quasisquare Wave Energy Recovery Drive Circuits for Piezoelectric Actuators", IEEE Trans. Ultrason., Ferroelectr., Freq. Control, vol. 52, no. 8, 2005.

[14] M. Karpelson, G.-Y. Wei, R. J. Wood, "Driving high voltage piezoelectric actuators in microrobotic applications," Sensors and Actuators A, vol. 176, pp. 78-89, 2012.

[15] B. Ducharne, L. Garbuio, M. Lallart, D. Guyomar, J.-Y. Gauthier and G. Sebald, "Nonlinear technique for energy exchange optimization in piezoelectric actuators", IEEE Trans. Power. Elec., Vol. 28(8), pp. 39413948, 2013.

[16] Y.P. Liu, D. Vasic. Small power Step-up Converter for driving flapping wings of the Micro Robotic Insects, IEEE ECCE 2012, Raleigh, North Carolina USA, 15-20 September 2012.

[17] D. Vasic, Y.-P. Liu, Denis Schwander, François Costa. Piezoelectric Transformer-based DC/DC Converter with improved Burst-Mode Control, IEEE ECCE 2013, Denver, CO, USA, 15-19 September 2013.

[18] Y.P. Liu, D. Vasic, F. Costa. Self-Resonant Step-up DC/DC Converter for driving flapping wings of the Micro Robotic Insects. World Congress on Biomimetic, Artificial Muscles and Nano-Bio 2011, Cergy-Pontoise France, 25-27 October 2011.

[19] W.-C. Su, and C.-L. Chen, "ZVS for PT backlight inverter utilizing high-order current harmonic," IEEE Trans. Power Electron., vol. 23, no. 1, pp. 4-10, 2008.

[20] D. Campolo, M. Sitti, and R. S. Fearing, "Efficient charge recovery method for driving piezoelectric actuators with quasi-square waves," IEEE Trans. Ultrasonics, Ferroelectrics, and Frequency Control, vol. 50, no. 3, pp. 237-244, March 2003.

[21] Y.-P. Liu, D. Vasic, F. Costa, "Wideband ZVS half-bridge circuit for piezoelectric transformers with small inductance," Electronics Letters, vol. 48, no. 9, pp.523-524, 2012.

[22] Y.-P. Liu, D. Vasic, W.-J. Wu, F. Costa, and C.-K Lee, "Design of fixed-frequency controlled radial-mode stacked disk-type piezoelectric transformers for DC/DC converter application", Smart Materials and Structures, vol. 18, no.8, 085025, 2009.

[23] R.-L. Lin, "Piezoelectric transformer characterization and application of electronic ballast," PhD Dissertation Virginia Polytechnic Institute and State University, USA, 2001. 